This is the accepted version of the following article:

Catalysis Today 243 (2015) 85-91, which has been published in final form at http://www.sciencedirect.com/science/article/pii/S0920586114004799.

Graphical Abstract

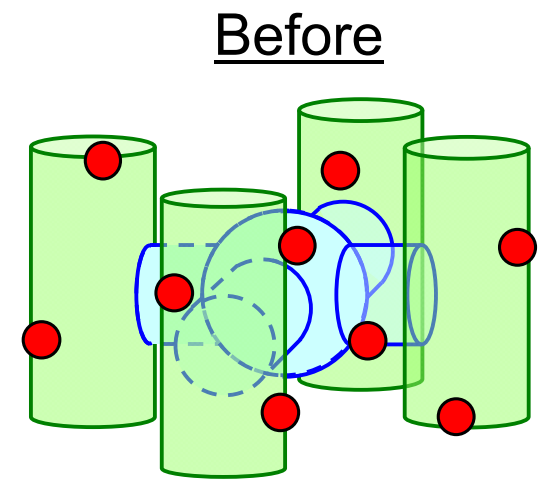

Post-synthetic acid-treatment

Pore system of MSE-type zeolite

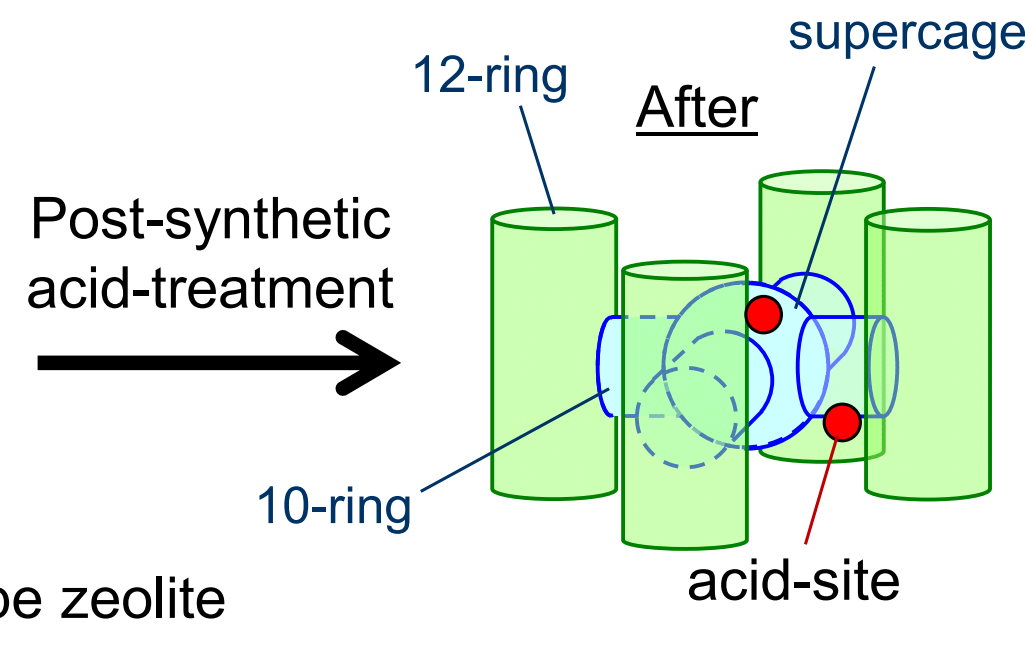




\title{
Remarkable enhancement of catalytic activity and selectivity of MSE- type zeolite by post-synthetic modification
}

\author{
Yoshihiro Kubota, ${ }^{*}$, Satoshi Inagaki, ${ }^{1}$ Yuji Nishita, ${ }^{1}$ Keiji Itabashi, ${ }^{2}$ Yasuyuki Tsuboi, ${ }^{1}$ \\ Tuan Syahylah Tuan Sulong, ${ }^{1}$ and Tatsuya Okubo ${ }^{2}$ \\ 1. Division of Materials Science and Chemical Engineering, Graduate School of \\ Engineering, Yokohama National University, Tokiwadai 79-5, Hodogaya-ku, Yokohama \\ 240-8501 Japan. \\ 2. Department of Chemical System Engineering, The University of Tokyo, 7-3-1, Bunkyo-ku, \\ Tokyo 113-8656, Japan \\ e-mail: kubota@ynu.ac.jp Phone \& Fax: +81-45-339-3941
}

\begin{abstract}
Besides conventional MCM-68, Al-rich MSE-type zeolites with a 12-10-10-ring micropore system were successfully synthesized in a remarkably short crystallization period by some different synthetic methods: (1) hydrothermal conversion of an FAUtype zeolite with the aid of the dipyrrolidinium-type organic structure-directing agent (OSDA) and (2) hydrothermal synthesis without using any OSDA with the aid of seed crystals. The dealumination behaviors during post-synthetic acid-treatments as well as the properties of the products differed depending on the synthetic method. The dealuminated version of each Al-rich MSE-type zeolite showed a high level of coking resistance in addition to a significant yield of propylene in the hexane cracking reaction, and the MSE synthesized under OSDA-free conditions showed the best catalytic performance among three different MSE-type zeolites after post-synthetic modification. The Al-rich MSE products obtained in this work are promising parent materials for industrial applications as highly selective and long-lived catalysts.
\end{abstract}

Key words: MSE-type zeolite; Organic structure-directing agent; OSDA-free synthesis; Dealumination; Hexane cracking; Coking resistance 


\section{Introduction}

The properties of zeolites depend on the method of preparation including starting gel composition and synthesis conditions. For example, the synthesis using organic structuredirecting agent (OSDA) usually gives high-silica zeolites while OSDA-free synthesis gives materials with much lower silica contents [1]. Even in the synthesis using an OSDA, Alrich (relatively low-silica) zeolite sometimes crystallizes under some conditions. In all cases, some post-synthetic modifications are necessary for preparing catalysts that have appropriate amount of active sites, proper hydrophobicity and stability. As pointed out by Valtchev et al. [2], the widening window of post-synthetic options enables the preparation of zeolites with application-specific properties. We have found that zeolites with MSE topology (the "type material" is MCM-68) offer interesting examples of the OSDAassisted and OSDA-free syntheses, post-synthetic modifications, and catalytic applications.

MSE is a new type of three-dimensional zeolite framework with a $12 \times 10 \times 10$-ring $(12 \times 10 \times 10 \mathrm{R})$ channel system [3]. This framework has a characteristic structure in which a straight $12 \mathrm{R}$ channel intersects with two independent tortuous $10 \mathrm{R}$ channels and, in addition, possesses an $18 \mathrm{R} \times 12 \mathrm{R}$ supercage which is accessible only through $10 \mathrm{R}$ channels [4]. Zeolites with this type of framework (e.g. MCM-68) are known to exhibit unique acid catalytic properties $[5,6]$ and are potentially useful as shape-selective catalysts for the alkylation of aromatics [7-9] as well as for the production of propylene by naphtha cracking [10]. Their use as hydrocarbon traps has also been reported [11]. In addition, Tisubstituted MCM-68 has demonstrated performance superior to that of TS-1 ([Ti]-MFI) for the oxidation of phenol and olefins with $\mathrm{H}_{2} \mathrm{O}_{2}$ as an oxidant [12].

MCM-68, a typical MSE-type zeolite, has been synthesized under hydrothermal conditions using $N, N, N^{\prime}, N$ '-tetraethyl-exo,exo-bicyclo[2.2.2] oct-7-ene-2,3:5,6-dipyrrolidin -ium diiodide $\left(\mathrm{TEBOP}^{2+}\left(\mathrm{I}^{-}\right)_{2}\right)$ as the OSDA [4,7,13-15]. The gel composition window for the successful crystallization of pure MCM-68 is very narrow and the Si/Al molar ratio of the product is limited to the range of 9 to 12 . We have previously succeeded in overcoming this limitation by utilizing the steam-assisted crystallization (SAC) [16-19] to obtain a precursor of pure-silica version of the MSE topology (YNU-2P) or its stabilized microporous version (YNU-2) [14,20]. Even so, the current requirement for a crystallization stage spanning 14 days or more during the synthesis of MCM-68 had remained an important unresolved issue. This has recently been solved in some ways, parts of which are reported in this paper. It should be noted that the MSE-type zeolite has also been synthesized as UZM-35 by charge density mismatch [21] with a simple OSDA, dimethyldipropylammonium [22]. In addition, continuous efforts to avoid using TEBOP ${ }^{2+}$ are being made by Exxonmobil researchers [23]. 
A main target product in this work is propylene (propene), which is an important synthetic intermediate for petrochemicals and functional organic materials. Currently, worldwide propylene production comes from steam cracking (ca. 70\%), refinery fluid catalytic cracking (FCC) (ca. 28\%), and other deliberate processes (ca. 2\%) such as propane dehydrogenation and metathesis [24,25]. It is well known that propylene yield in the fluid catalytic cracking (FCC) processes has been enhanced using zeolite Y (FAU topology [3]) and ZSM-5 zeolite (MFI topology [3]) catalysts by the control of the synthetic parameters, post-synthetic treatment such as steaming, and further modification with alkaline-earth or rare-earth metals. Over the past decade, new types of zeolite materials with large (12-ring; 12R) or extra-large $(>12 R)$ micropores have been synthesized and tested as FCC catalysts or as their additives [10]. Based on the various results, zeolite frameworks with multi-dimensional $10 \mathrm{R}$ or $12 \mathrm{R}$ micropores would be suitable for propylene production in the FCC process, and the zeolite catalyst with MSE topology is a promising candidate. The cracking of $n$-alkane, especially $n$-hexane, is often examined as a model reaction for the FCC catalytic test [26-30].

In this study, we focus on the remarkable enhancement of catalytic properties of some different versions of MSE-type materials for hexane cracking by post-synthetic treatments.

\section{Experimental}

\subsection{Chemicals and materials}

The commercially available reagents were used as received without further purification. The suppliers and cautions are described in each section when necessary.

\subsection{Synthesis of MCM-68 as a conventional MSE-type zeolite}

MCM-68 zeolite was synthesized as follows: colloidal silica (Ludox HS-40, DuPont, 40 $\left.\mathrm{wt} \% \mathrm{SiO}_{2}, 6.01 \mathrm{~g}, 100.0 \mathrm{mmol}\right)$, de-ionized water $(40 \mathrm{~mL})$ and $\mathrm{Al}(\mathrm{OH})_{3}$ (Pfaltz \& Bauer, $780 \mathrm{mg}, 10.0 \mathrm{mmol}$ ) were mixed in a $180-\mathrm{mL}$ Teflon beaker, and stirred for $10 \mathrm{~min}$. Aqueous $\mathrm{KOH}$ solution (5.93 $\mathrm{mmol} \mathrm{g}^{-1}, 6.32 \mathrm{~g}, 37.5 \mathrm{mmol}$ ) was added to the solution, and stirred for further $30 \mathrm{~min}$. Then, TEBOP ${ }^{2+}\left(\mathrm{I}^{-}\right)_{2}(10.0 \mathrm{mmol})$ was added as an OSDA, and the mixture was stirred for another $4 \mathrm{~h}$. The resulting mixture with a molar composition: $1.0 \mathrm{SiO}_{2}-0.1 \mathrm{TEBOP}^{2+}\left(\mathrm{I}^{-}\right)_{2}-0.375 \mathrm{KOH}-0.1 \mathrm{Al}(\mathrm{OH})_{3}-30 \mathrm{H}_{2} \mathrm{O}$ was taken into a $125-\mathrm{mL}$ Teflon-lined autoclave, and kept statically at $160{ }^{\circ} \mathrm{C}$ for 16 days in a convection oven. After cooling the autoclave to room temperature, the obtained solid was separated by centrifuging, washed several times with de-ionized water, and dried overnight. The assynthesized MCM-68 zeolite was obtained as white powder (6.04 g). 
To remove the OSDA occluded in the pore, the as-synthesized MCM-68 was kept in a muffle furnace, and heated stepwise as follows: the temperature was raised from room temperature to $650{ }^{\circ} \mathrm{C}$ under $1{ }^{\circ} \mathrm{C} \min ^{-1}$ of the ramping rate, and maintained at the same temperature for $10 \mathrm{~h}$. Finally, the sample was cooled to room temperature to give a calcined sample as white powder $(\mathrm{Si} / \mathrm{Al}=11-12)$.

\subsection{Synthesis of MSE-type zeolite (YNU-3) via hydrothermal conversion of FAU-type zeolite [15]}

A typical synthetic procedure of the hydrothermal conversion of FAU-type zeolite (Tosho, HSZ-360HUA; $\mathrm{Si} / \mathrm{Al}=6.7)$ is as follows: de-ionized water $(40 \mathrm{~mL}$ ) and aqueous $\mathrm{KOH}$ solution $\left(5.93 \mathrm{mmol} \mathrm{g}^{-1}, 6.32 \mathrm{~g}, 37.5 \mathrm{mmol}\right)$ were mixed in a $125-\mathrm{mL}$ Teflon beaker. To this mixture, TEBOP ${ }_{2}^{+}\left(\mathrm{I}^{-}\right)_{2}(5.58 \mathrm{~g}, 10.0 \mathrm{mmol})$ was added and stirred for $30 \mathrm{~min}$, and then as-synthesized [Al]-MCM-68 (0.30 g, $5.0 \mathrm{wt} \%$ of FAU-type zeolite) was added as the seed crystal. Finally, FAU-type zeolite $(6.01 \mathrm{~g})$ was added and the mixture was stirred for another $4 \mathrm{~h}$. The resulting mixture with a molar composition: $1.0\left(\mathrm{SiO}_{2}-\mathrm{Al}_{2} \mathrm{O}_{3}\right)$ $0.1 \mathrm{TEBOP}^{2+}\left(\mathrm{I}^{-}\right)_{2}-0.375 \mathrm{KOH}-30 \mathrm{H}_{2} \mathrm{O}$ was taken into a $125-\mathrm{mL}$ Teflon-lined autoclave, and kept statically at $160{ }^{\circ} \mathrm{C}$ for 5 days in a convection oven. After cooling the autoclave down to room temperature, the precipitated solid was separated by centrifugation, washed thoroughly with de-ionized water, and dried overnight to give the as-synthesized MSEtype zeolite $(6.38 \mathrm{~g})$ as a white powder. This material is denoted as-synthesized YNU-3 [15] to distinguish from conventional MCM-68 because of its unique properties. After removing the OSDA occluded in the pore from the as-synthesized YNU-3 in the same way as that for MCM-68, a calcined YNU-3 sample was obtained as white powder $(\mathrm{Si} / \mathrm{Al}=c a$. 7).

\subsection{Synthesis of MSE-type zeolite under OSDA-free conditions [25 31]}

Aqueous solutions of $\mathrm{NaOH}\left(6.32 \mathrm{mmol} \mathrm{g}^{-1} ; 12.68 \mathrm{~g}, 84.06 \mathrm{mmol}\right)$ and $\mathrm{KOH}(5.96$ mmol g-1; $996 \mathrm{mg}, 5.94 \mathrm{mmol})$ were mixed with distilled water $(43.84 \mathrm{~g}, 3.00 \mathrm{~mol})$ in a Teflon cup and sodium aluminate $(\mathrm{Al} / \mathrm{NaOH}=0.77 ; 443 \mathrm{mg})$ was dissolved in the mixture. The resulting clear solution was transferred to a mortar and calcined MCM-68 seeds (901 $\mathrm{mg}$ ) were added. After the entire mixture was homogenized using a mortar and pestle for 10 minutes, Cab-O-Sil M5 (9.01 g, $150 \mathrm{mmol}$ ) was added and the combined ingredients were again homogenized in the same manner for 20-30 minutes. The mixture was then transferred to a $60-\mathrm{mL}$ stainless steel autoclave and subjected to hydrothermal treatment at $140{ }^{\circ} \mathrm{C}$ for $48 \mathrm{~h}$ under static conditions and autogeneous pressure. The product was 
subsequently filtered, washed thoroughly with hot distilled water and dried at $60{ }^{\circ} \mathrm{C}$ to obtain pure MSE $\operatorname{OSDAF}_{\text {( }}(2.16 \mathrm{~g}$ ). The yield was $21 \%$ (see Section 3.1).

\subsection{Ion-exchange of MSE-type materials into their ammonium-forms}

Ion exchange from the calcined sample to its $\mathrm{NH}_{4}$-form was carried out using $\mathrm{NH}_{4} \mathrm{NO}_{3}$ solution as follows: $\mathrm{NH}_{4} \mathrm{NO}_{3}(4.0 \mathrm{~g})$ and the calcined sample $(2.0 \mathrm{~g})$ were suspended in $\mathrm{H}_{2} \mathrm{O}(100 \mathrm{~mL})$ in a $250-\mathrm{mL}$ polypropylene bottle. The bottle was capped tightly and allowed to stand at $80{ }^{\circ} \mathrm{C}$ for $24 \mathrm{~h}$ with occasional purge of pressure and careful shaking. After cooling down, the sample was separated by filtration, and washed with de-ionized water. This process was repeated twice. The sample was filtered, washed thoroughly with water, and dried overnight at room temperature to give MCM-68 in $\mathrm{NH}_{4}$-form (MCM68_cal_IE), YNU-3 in $\mathrm{NH}_{4}$ form (YNU-3_cal_IE), and the $\mathrm{NH}_{4}$-form of $\mathrm{MSE}_{\mathrm{OSDAF}}$

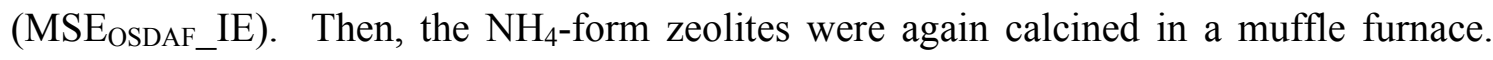
The temperature was raised from room temperature to $550^{\circ} \mathrm{C}$ over a period of $4 \mathrm{~h}$, and kept at the same temperature for $6 \mathrm{~h}$ to give MCM-68 in H-form (MCM-68_cal_IE_cal, $\mathrm{Si} / \mathrm{Al}=11)$, YNU-3 in H-form (YNU-3_cal_IE_cal, Si/Al = 7.4), and MSE OSDAF_IE_cal $(\mathrm{Si} / \mathrm{Al}=7.3)$.

\subsection{Direct dealumination of MCM-68 and YNU-3 by acid-treatment}

The dealumination of the samples obtained in the Sections 2.2 and 2.3 were carried out by treating with appropriate concentrations between 0.5 and $6.7 \mathrm{~mol} \mathrm{~L}^{-1} \mathrm{HNO}_{3}$ solution (30-60 mL (g-sample $\left.)^{-1}\right)$ under the reflux conditions in a $200-\mathrm{mL}$ round-bottom flask immersed in an oil bath $\left(130^{\circ} \mathrm{C}\right)$ for $2-24 \mathrm{~h}$. After filtration, thorough washing with water, and drying at $80{ }^{\circ} \mathrm{C}$, the dealuminated sample was obtained. For example, the treatment with $0.5 \mathrm{~mol} \mathrm{~L}{ }^{-1} \mathrm{HNO}_{3}$ solution for $2 \mathrm{~h}$ gave MCM-68 with $\mathrm{Si} / \mathrm{Al}$ ratio 64.5, and the dealumination of the calcined $\mathrm{YNU}-3(\mathrm{Si} / \mathrm{Al}=7.8)$ was carried out by treating with 6.7 mol L ${ }^{-1} \mathrm{HNO}_{3}$ solution $\left(60 \mathrm{~mL}(\mathrm{~g} \text {-sample })^{-1}\right)$ for $24 \mathrm{~h}$ gave the dealuminated $\mathrm{YNU}-3$ ( $\mathrm{Si} / \mathrm{Al}$ =69.4), which were employed in the catalytic reaction.

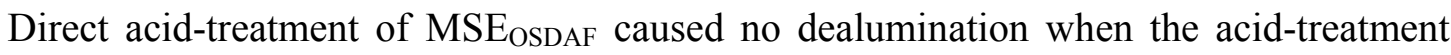
conditions are too mild while severe conditions resulted in the framework collapse along with dealumination [25] (see Section 3.2). 


\subsection{Steaming of $M S E_{O S D A F}$ in $\mathrm{NH}_{4}{ }^{+}$-form}

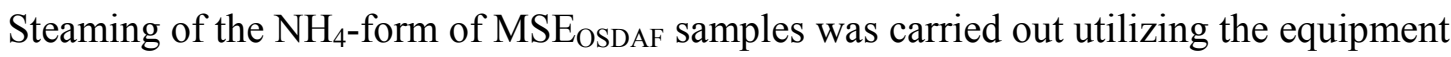
similar to down-flow quartz tube reactor. Steam $(7.3-12.3 \mathrm{kPa})$ was supplied at $700{ }^{\circ} \mathrm{C}$ for $24 \mathrm{~h}$ and the resultant MSE-type material was denoted MSEOSDAF_IE_ST.

\subsection{Dealumination by acid treatment after steaming}

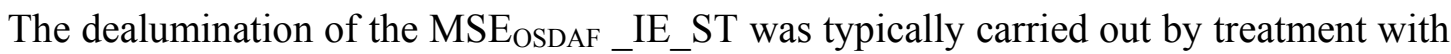
a $6.0 \mathrm{~mol} \mathrm{~L}^{-1} \mathrm{HNO}_{3}$ solution $\left.(60 \mathrm{~mL} \text { (g-sample })^{-1}\right)$ in a $200 \mathrm{~mL}$ round bottom flask under reflux conditions in a $130{ }^{\circ} \mathrm{C}$ oil bath for $2-24 \mathrm{~h}$. The acid-treated sample was denoted MSEOSDAF_IE_ST_AT. As a typical example, the MSE OSDAF_IE_ST_AT (Si/Al = 66.9) was employed in the catalytic reaction.

\subsection{Characterization}

The crystallinity and phase purity of the zeolite catalysts were examined by powder Xray diffraction (XRD) on an Ultima-IV (Rigaku) using $\mathrm{CuK} \alpha$ radiation at $40 \mathrm{kV}$ and 20 $\mathrm{mA}$. The Si/Al molar ratios in the bulk were measured by means of inductively coupled plasma, atomic emission spectrometer (ICP-AES, ICPE-9000, Shimadzu). The coke contents on the used catalysts were determined by thermogravimetry (TG, Thermo plus EVO II TG8120, Rigaku). The weight loss from 400 to $800{ }^{\circ} \mathrm{C}$ in the used catalyst was defined as the amount of coke formed during the catalytic reaction. The morphologies and particle sizes of zeolite catalysts were observed by field-emission scanning electron microscope (FE-SEM) on a JSM-7001F (JEOL) or an S-4800 (Hitachi). Nitrogen adsorption and desorption isotherms at $-196^{\circ} \mathrm{C}$ were measured for the samples pre-treated at $400^{\circ} \mathrm{C}$ for 2-6 h on a Belsorp MAX gas adsorption instrument. The specific surface area $\left(S_{\mathrm{BET}}\right)$ and micropore volume $\left(V_{\text {micro }}\right)$ were calculated using the BET method and the $t$-plot method, respectively. The number of acid sites was measured by using the temperatureprogrammed desorption (TPD) of ammonia on a BELCAT-B (Japan Bel Inc.). The catalyst employed was preheated at $500{ }^{\circ} \mathrm{C}$ prior to the measurement. The TPD data were

collected at a ramping rate of $10^{\circ} \mathrm{C} \mathrm{min}^{-1}$. The number of acid sites was determined from the area of $h$-peak $[32,33]$ in their profiles.

\subsection{Catalytic reaction}

An appropriate amount of each zeolite catalyst was pelletized without any binder, roughly crushed and then sieved to obtain particles 500-600 $\mu \mathrm{m}$ in size. Hexane cracking was performed under atmospheric pressure in a down-flow quartz-tube microreactor with an $8 \mathrm{~mm}$ inner diameter. Prior to running the reaction, $100 \mathrm{mg}$ of catalyst pellets were 
packed in the fixed bed of the reactor and preheated at $650{ }^{\circ} \mathrm{C}$ for $1 \mathrm{~h}$ in a stream of air. The reaction was performed at $650{ }^{\circ} \mathrm{C}$ for $305 \mathrm{~min}$ in a stream of helium containing an appropriate amount of hexane $\left.(\mathrm{W} / \mathrm{F}=19.6 \mathrm{~g} \text {-cat. } \mathrm{h} \text { (mol-hexane })^{-1}\right)$. Following the reaction at $650{ }^{\circ} \mathrm{C}$, the system was cooled to room temperature in a helium stream and the used catalyst was recovered. The reactants and products were analyzed on an HP-PLOT Q capillary column (i.d. $0.53 \mathrm{~mm}$; length $30 \mathrm{~m}$; Agilent Technology) using a GC-14B (Shimadzu) with a flame ionization detector. The conversion of hexane and the selectivity of each catalyst were calculated on a carbon basis relative to the initial amount of hexane.

\section{Results and discussion}

\subsection{Synthesis of parent MSE-type zeolites}

Powder XRD patterns of the MSE-type zeolites synthesized by different techniques are shown in Fig. 1. The Si/Al ratios of the conventional MCM-68 are quite reproducible and within the range of 11-13 for as-synthesized and calcined samples. The conventional MCM-68 was readily dealuminated by a treatment with diluted nitric acid at $80{ }^{\circ} \mathrm{C}$ for 224h. In this paper, the dealuminated MCM-68 $(\mathrm{Si} / \mathrm{Al}=64.5)$ was used as a representative dealuminated sample.

Fig. $1 \mathrm{~b}$ shows the XRD patterns of the products resulting from syntheses at $160^{\circ} \mathrm{C}$ for 5 days using FAU-type zeolite $(\mathrm{Si} / \mathrm{Al}=6.7)$ as the $\mathrm{SiO}_{2}-\mathrm{Al}_{2} \mathrm{O}_{3}$ source. In our previous study, it has been speculated that aluminosilicate oligomers formed by the hydrolysis of FAUtype zeolites require $\mathrm{Si} / \mathrm{Al}$ molar ratios with a specific range to avoid the formation of other zeolite phases. In addition, no crystallization takes place if the concentration of aluminate species is insufficient. Fig. 2 shows the crystallization curve associated with the hydrothermal conversion of FAU into MSE to give [Al]-YNU-3 as well as that with the normal synthesis of typical MCM-68, as determined by XRD peak intensities (approximately $21.7^{\circ} 2 \theta$, indexed to 420 in the MSE framework) of the products crystallized during the time span of 1 to $16 \mathrm{~d}$. It should be noted that an MSE phase appeared after only $1 \mathrm{~d}$ of hydrothermal crystallization, and that extending the crystallization time to $3 \mathrm{~d}$ gave a pure MSE phase with a high degree of crystallinity, whereas the induction time is more than $9 \mathrm{~d}$ and the crystallization period as long as $14 \mathrm{~d}$ is necessary to guarantee the sufficient crystallization when starting from amorphous $\mathrm{SiO}_{2}$ $\mathrm{Al}_{2} \mathrm{O}_{3}$ source. The crystallization kinetics has been discussed in detail in our previous paper [15], in which it was suggested that the FAU-type zeolite is acting as a $\mathrm{SiO}_{2}-\mathrm{Al}_{2} \mathrm{O}_{3}$ source dissolved rapidly in the alkaline medium and the FAU-originated precursor may already have some minimum-sized host structures that could incorporate the OSDA as a 
guest, probably due to the enhanced crystallization rate by the presence of a large number of $4 \mathrm{R}$ precursors.

Fine tuning of starting gel including alkaline contents enabled the seed-assisted, OSDAfree synthesis of MSE-type zeolite, and the typical XRD pattern is shown in Fig. 1c. The optimal ratio of $\mathrm{K} /[\mathrm{Na}+\mathrm{K}]$ was 0.067 as described in Experimental Section (2.4). Quite reproducible synthesis was possible even when the synthetic scale was increased such that the quantities involved were five times larger than our initial investigations (from 30 $\mathrm{mmol}-\mathrm{SiO}_{2}$ to $150 \mathrm{mmol}-\mathrm{SiO}_{2}$ ), affording pure MSE phases in constant yields. The product yields (defined here as the mass of dried product per a total mass of starting silica, sodium aluminate, and seed) are within the range of $20-21 \%$ and quite reproducible under the current synthesis conditions.

It should be noted that the MSE frameworks are stable during simple calcination regardless of the synthesis technique. However, only $\mathrm{MSE}_{\mathrm{OSDAF}}$ was not always stable during the dealumination by acid-treatments (see Section 3.2).

\subsection{Dealumination behaviors of MSE-type zeolites synthesized with and without using an OSDA}

In the case of conventional MSE hydrothermally synthesized by the OSDA-assisted technique (typical Si/Al is around 11, corresponding to 9-10 Al sites/unit cell), framework aluminum atoms are readily removed by liquid phase nitric acid treatment at $80-100{ }^{\circ} \mathrm{C}$ to give dealuminated sample (denoted MCM-68_AT). With the MSE OSDAF (Fig. 3a; typical $\mathrm{Si} / \mathrm{Al}$ is $6-7$ corresponding to $14-16 \mathrm{Al}$ sites/unit cell), however, the framework exhibits significant collapse during dealumination (Fig. 3b).

The steaming of an $\mathrm{NH}_{4}$-form was found to be an effective means of avoiding this collapse. The MSE $\mathrm{OSDAF}$ underwent ion exchange with an $\mathrm{NH}_{4} \mathrm{NO}_{3}$ solution at $80{ }^{\circ} \mathrm{C}$ to give the $\mathrm{NH}_{4}$-form (MSE $\mathrm{OSDAF}_{-} \mathrm{IE}$; Fig. 3c). During steaming of this $\mathrm{NH}_{4}$-form, the steam $\left(7.3-12.3 \mathrm{kPa}\right.$ ) was typically supplied at $700{ }^{\circ} \mathrm{C}$ for $24 \mathrm{~h}$ and the resulting material was

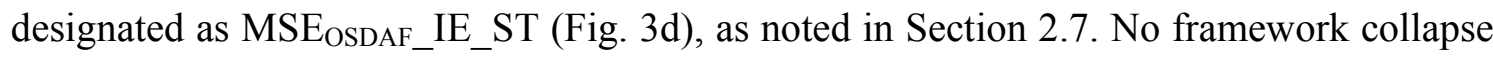
was observed during this steaming, while the Si/Al ratio (as per ICP data) of the sample did not increase. Subsequent $\mathrm{HNO}_{3}$ treatment resulted in a remarkable increase in the $\mathrm{Si} / \mathrm{Al}$ ratio (Fig. 3e) even though the MSE framework remained intact. The acid treatment procedure consisted of heating the steamed sample at $80{ }^{\circ} \mathrm{C}$ for $2 \mathrm{~h}$ in a $6 \mathrm{~mol} \mathrm{~L}^{-1} \mathrm{HNO}_{3}$ solution. In this manner, dealuminated samples were obtained and denoted as

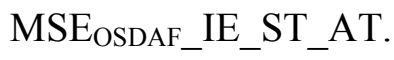

There is a reason for the framework stabilization of MSE $E_{\text {OSDAF }}$ which was observed to result from steaming. We believe that the migration of $\mathrm{Si}(\mathrm{OH})_{4}$ takes place during 
steaming to repair site defects by condensation reactions between $\mathrm{Si}(\mathrm{OH})_{4}$ and silanols [17,31].

Table 1 lists some representative results regarding dealumination behaviors of various MSE-type zeolites. The conventional MCM-68 (initial Si/Al $=11.0$ ) was quite readily dealuminated with dilute $\mathrm{HNO}_{3}$ (see Experimental Section 2.6), whereas the dealumination of YNU-3 (an MSE analogue with initial Si/Al = 7.8, see Experimental Section 2.6) and

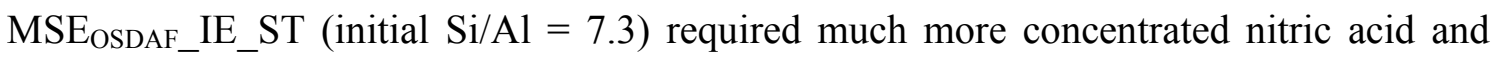
moreover the maximum $\mathrm{Si} / \mathrm{Al}$ ratio did not exceed 80 even when using $6.0 \mathrm{~mol} \mathrm{~L}{ }^{-1} \mathrm{HNO}_{3}$ (see Experimental Section 2.8). Based on our previous investigations and a general knowledge of catalysis, the appropriate $\mathrm{Si} / \mathrm{Al}$ ratio for catalytic use is very often in the

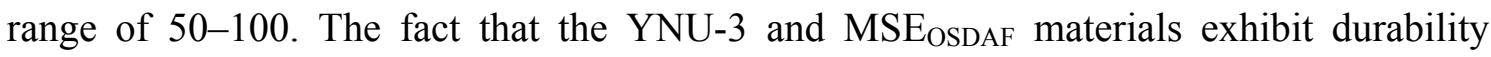
during additional dealumination is therefore highly desirable and promising with regard to future catalytic applications. There may be both microscopic (such as 'siting' of Al in the framework) and macroscopic (related to particle size and morphology) reasons for the observed dealumination resistance.

Fig. 4 shows the FE-SEM images of MCM-68, YNU-3, and MSEOSDAF in the same magnification. (The images in different magnifications are reported elsewhere [25].) The particle size of MCM-68 (50-100 nm) is much smaller than those of YNU-3 $(0.5-1.0 \mu \mathrm{m}$ as aggregates) and $\mathrm{MSE}_{\mathrm{OSDAF}}$ (ca. $200 \mathrm{~nm}$ ), which is consistent with the particularly facile dealumination from MCM-68.

Fig. 5 shows nitrogen adsorption-desorption isotherms of MCM-68, YNU-3, and

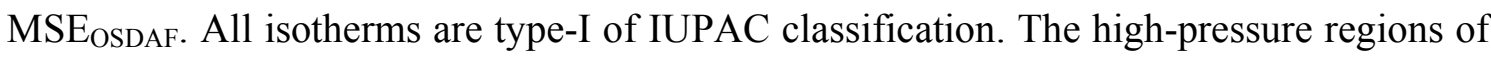
the isotherms for MCM-68 (Fig. 5a) indicate prominent sign of inter-particle voids, which is consistent with the particularly small particle size. Furthermore, the largest external surface area of MCM-68 is also consistent with the smaller particle size.

\subsection{Hexane cracking over various MSE-type zeolite catalysts}

Fig. 6 shows the variation over time in both hexane conversion and product yield during the cracking of $n$-hexane at $650{ }^{\circ} \mathrm{C}$ over various MSE-type zeolite catalysts. The result of thermal cracking is also shown for comparison. Although the system composed of MCM68 _cal_IE_cal $(\mathrm{Si} / \mathrm{Al}=11)$ or YNU-3_cal IE_cal $(\mathrm{Si} / \mathrm{Al}=7.4)$ exhibited catalytic activity sufficient for the hexane cracking process, it was quite rapidly deactivated such that the reaction rate obtained was equal to the thermal cracking rate of $n$-hexane at $650{ }^{\circ} \mathrm{C}$ (Fig. $6 \mathrm{a}$, $6 \mathrm{~b}$, and $6 \mathrm{c})$. This deactivation was likely caused by the large amount of coke (>100 $\mathrm{mg}$ coke (g-catalyst) ${ }^{-1}$ after $305 \mathrm{~min}$ of the reaction at $650{ }^{\circ} \mathrm{C}$ over MCM-68 and YNU-3) formed on the catalyst. In contrast, the rapid deactivations were significantly suppressed 
by dealumination of MCM-68 and YNU-3. In particular, dealuminated YNU-3 ( $\mathrm{Si} / \mathrm{Al}=$ 69.4) maintained its initial catalytic activity after $305 \mathrm{~min}$ and showed a minimal amount of coke formation (1.8 mg-coke (g-catalyst) ${ }^{-1}$ after $305 \mathrm{~min}$ of reaction). Although the system composed of dealuminated MCM-68 $(\mathrm{Si} / \mathrm{Al}=64.5)$ exhibited catalytic activity sufficient for the hexane cracking process, it was significantly deactivated such that the hexane conversion at the point of 305 min was below 50\%. Again, this deactivation was likely caused by the relatively large amount of coke (33.4 mg-coke (g-catalyst) ${ }^{-1}$ after 305 min of reaction) formed on the catalyst. Looking at the product selectivity in Fig. 7 at the point of $50 \%$ hexane conversion at $650{ }^{\circ} \mathrm{C}$, the dealuminated YNU-3 showed higher propylene selectivity ( $c a .44 \%$ ) and lower BTX selectivity (less than $1 \%$ ) as compared to dealuminated MCM-68 ( $c a .38 \%$ and $c a .3 \%$, respectively), indicating that dealuminated YNU-3 may be a candidate for practical applications.

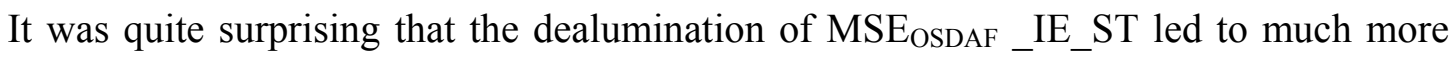
improved catalytic activity and comparatively reduced coke formation (3.3 mg-coke (gcatalyst $^{-1}$ after 305 min of reaction). Hexane conversion was always much higher than that over dealuminated YNU-3. Looking at the product selectivity in Fig. 7 at the point of $70 \%$ hexane conversion at $650{ }^{\circ} \mathrm{C}$, the dealuminated MSE OSDAF (= MSE OSDAF_IE_ST_AT) showed higher propylene selectivity (ca. 44\%; the same level as less active dealuminated[Al]-YNU-3) and lower BTX selectivity (1\%) as compared to dealuminated MCM-68 (ca. $41 \%$ and ca. $3 \%$, respectively).

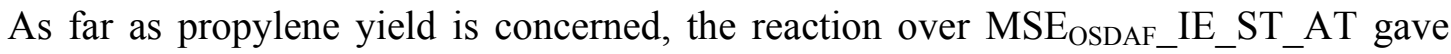
propylene in much higher yields than that over the other MSE-type catalysts at any timecourse (Fig. 6), indicating that dealuminated-[Al]-MSE OSDAF $_{\text {may be a viable candidate for }}$ application as a long-lived paraffin-cracking catalyst for the selective production of propylene.

\subsection{Correlation between acidic properties and catalytic perdormances}

Fig. 8 present the ammonia temperature-programmed desorption $\left(\mathrm{NH}_{3}-\mathrm{TPD}\right)$ profiles for the MSE materials. The quantity of acid sites (or acid amounts) estimated from the $\mathrm{NH}_{3}$ TPD data, based on the area of the so-called $h$-peak $[32,33]$ in each profile, were 0.238 , 0.106 and $0.076 \mathrm{mmol} \mathrm{g}^{-1}$ for MCM-68_AT, YNU-3_AT and MSEOSDAF_IE_ST_AT. It is interesting to note that the acid amounts of the modified and optimized high-performance catalysts as determined by $\mathrm{NH}_{3}$-TPD were especially small for MSE materials and were only one-half to one-third of the amounts expected from the elemental analysis values derived from ICP data. This indicates that these materials contained significant quantities of undetectable acid site and that the activities per detectable acid site (corresponding to 
the actual turnover numbers) of the optimized MSE OSDAF materials are quite large compared to the other lower-performance materials investigated in this work, including OSDA-assisted MSE.

In order to explain these findings, further investigations regarding the distribution of $\mathrm{Al}$ sites based on microscopic and macroscopic studies are required.

The acidity in connection with accessibility and diffusivity has been studied by Žilková et al. [5], in the case of toluene disproportionation as well as toluene and $p$-xylene alkylation over zeolites with one- to three dimensional $10 \mathrm{R}$ and $12 \mathrm{R}$ channels with and without cages, and those with 12-12-10R and 12-10-10R channel systems (SSZ-35, MCM58, mordenite, ZSM-5, beta, SSZ-33, and MCM-68). They concluded that channel architecture and acidity have to be always considered in parallel. The 1-D zeolites possessing cages such as SSZ-35 and MCM-58 were emphasized to have high stability against deactivation by limiting formation of bulky organic deposits while not significantly hindering the transport of reactants and products. Conversely, the faster deactivation of multi-dimensional channel structure including MSE topology by coke formation is pointed out. Since the MCM-68 catalyst in their paper has not been dealuminated, the rapid deactivation is consistent with our result (Fig. 6b and 7b) [34]. Gil et al. [6] investigated acid properties of MCM-58 and MCM-68 very carefully by means of IR spectroscopy using probe molecules, and compared with other 12R zeolites such as ZSM-12 and beta. Based on their results, the number of Brønsted and Lewis acid sites per unit cell of MCM$68(\mathrm{Si} / \mathrm{Al}=13)$ is 4.41 and 0.65 , respectively. The corresponding characterizations for YNU-3 and MSE OSDAF are under investigation.

\section{Conclusions}

MSE-type zeolites, with a 12-10-10-ring micropore system, were synthesized by three different methods. Conventional hydrothermal synthesis had a drawback of too long crystallization time as long as 12-16 days. This drawback has been overcome and Al-rich MSE-type zeolites were successfully synthesized in a remarkably short crystallization period by some different synthetic methods: (1) hydrothermal conversion of an FAUtype zeolite with the aid of the dipyrrolidinium-type organic structure-directing agent (OSDA) and (2) hydrothermal synthesis without using any OSDA with the aid of seed crystals. The MSE-type materials without dealumination treatments resulted in rapid deactivation during the hexane cracking reaction mainly due to heavy coke formation. Dealumination by post-synthetic acid treatment was thus effective to realize enhanced catalytic performance. The dealumination behaviors during post-synthetic acid-treatments as well as the properties of the products differed depending on the synthetic method. The 
dealuminated version of each Al-rich MSE-type zeolite showed a high level of coking resistance in addition to a significant yield of propylene in the hexane cracking reaction, and the order of catalytic performance after post-synthetic modification was "conventional MCM-68 < MSE synthesized by hydrothermal conversion of an FAU-type zeolite (YNU$3)<$ MSE synthesized under OSDA-free conditions (MSE OSDAF)". The Al-rich MSE

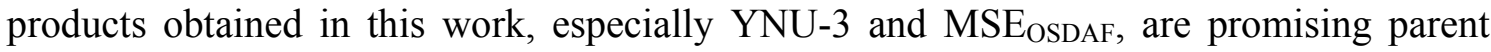
materials for industrial applications as highly selective and long-lived catalysts. In addition, the achievements reported in this paper also demonstrate the catalytic applicability of aluminum-rich zeolites that have been synthesized without using an OSDA and which are post-synthetically stabilized.

\section{Acknowledgements}

We wish to acknowledge the Nippon Chemical Industrial Co., Ltd. for partly supporting this work through financial assistance. This work was partly supported by New Energy and Industrial Technology Development Organization (NEDO).

\section{References}

[1] M.E. Davis and R.F. Lobo, Chem. Mater., 4 (1992) 756-768.

[2] V. Valtchev, G. Majano, S. Mintova, J. Pérez-Ramírez, Chem. Soc. Rev. 42 (2013) 263.

[3] Ch. Baerlocher, L. B. McCusker and D. H. Olson, Atlas of Zeolite Framework Types, Elsevier, Amsterdam, 6th edn, 2007, see also: http://www.iza-structure.org/databases/.

[4] D.L. Dorset, S.C.Weston, S.S. Dhingra, J. Phys. Chem. B 110 (2006) 2045.

[5] N. Žilková, M. Bejblová, B. Gil, S. I. Zones, A. W. Burton, C.-Y. Chen, M. MusilováPavlačková, G. Košová, J. Čejka, J. Catal. 266 (2009) 79.

[6] B. Gil, G. Košová, J. Čejka, Micropor. Mesopor. Mater. 129 (2010) 256.

[7] T. Shibata, S. Suzuki, H. Kawagoe, K. Komura, Y. Kubota, Y. Sugi, J.-H. Kim, G. Seo, Microporous Mesoporous Mater. 116 (2008) 216.

[8] T. Shibata, H. Kawagoe, H. Naiki, K. Komura, Y. Kubota, Y. Sugi, J. Mol. Catal. A 297 (2009) 80.

[9] S. Ernst, S. P. Elangovan, M. Gerstner, M. Hartmann, S. Sauerbeck, Abstr. 14th Int. Zeol. Conf. (2004) 982.

[10] S. Inagaki, K. Takechi and Y. Kubota, Chem. Commun. 46 (2010) 2662-2664.

[11] S. P. Elangovan, M. Ogura, S. Ernst, M. Hartmann, S. Tontisirin, M. E. Davis, T. Okubo, Micropor. Mesopor. Mater. 96 (2006) 210. 
[12] Y. Kubota, Y. Koyama, T. Yamada, S. Inagaki, T. Tatsumi, Chem. Commun. 44 (2008) 6224.

[13] D.C. Calabro, J.C. Cheng, R.A. Crane Jr., C.T. Kresge, S.S. Dhingra, M.A. Steckel, D.L. Stern, S.C. Weston, U.S. Pat., 2000, 6049018.

[14] Y. Koyama, T. Ikeda, T. Tatsumi, Y. Kubota, Angew. Chem. Int. Ed. 47 (2008) 1042.

[15] S. Inagaki, Y. Tsuboi, Y. Nishita, T. Syahylah, T. Wakihara, Y. Kubota, Chem. Eur. J. 19 (2013) 7780.

[16] P.R.H. Prasad Rao, M. Matsukata, Chem. Commun. 32 (1996) 1441

[17] P.R.H. Prasad Rao, K. Ueyama, M. Matsukata, Appl. Catal. A: General 166 (1998) 97.

[18] M. Matsukata, M. Ogura, T. Osaki, P. R. H. P. Rao, M. Nomura, E. Kikuchi, Top. Catal. 9 (1999) 77.

[19] M. Matsukata, M. Ogura, T. Osaki, E. Kikuchi, A. Mitra, Micropor. Mesopor. Mater. 48 (2001) 23.

[20] T. Ikeda, S. Inagaki, T. Hanaoka, Y. Kubota, J. Phys. Chem. C 114 (2010) 19641.

[21] M.B. Park, Y. Lee, A. Zheng, F.-S. Xiao, C.P. Nicholas, G.J. Lewis, S.B. Hong J. Am. Chem. Soc. 135 (2013) 2248.

[22] J.G. Moscoso, D.-Y. Jan, U.S. Pat. 2011, 7922997.

[23] S.C. Weston, K.G. Strohmaier, H.B. Vroman, U.S. Pat. 2013, 0115163 A1.

[24] J. Verstraete, V. Coupard, C. Thomazeau and P. Etienne, Catal. Today 106 (2005) 62.

[25] A. Corma, F.V. Melo, L. Sauvanaud, F.J. Ortega, Appl. Catal. A: Gen. 265 (2004) 195.

[26] S.M. Babitz, B.A. Williams, J.T. Miller, R.Q. Snurr, W.O. Haag, H.H. Kung, Appl. Catal. A 179 (1999) 71.

[27] T.F. Narbeshuber, H. Vinek, J.A. Lercher, J. Catal. 157 (1995) 388.

[28] A. Brait, K. Seshan, J.A. Lercher, Appl. Catal. A: General 169 (1998) 299.

[29] A. Brait, K. Seshan, H. Weinstabl, A. Ecker, J.A. Lercher, Appl. Catal. A: General 169 (1998) 315.

[30] M.-T. Tran, N.S. Gnep, G. Szabo, M. Guisnet, Appl. Catal. A: General 170 (1998) 49.

[31] Y. Kubota, K. Itabashi, S. Inagaki, Y. Nishita, R. Komatsu, Y. Tsuboi, S. Shinoda, T. Okubo, Chem. Mater. 26 (2014) 1250.

[32] M. Niwa, K. Katada, Catal. Surv. Jpn. 1 (1997) 215.

[33] M. Niwa, N. Katada, K. Okumura, Springer Series in Materials Science Vol. 141 (2010) [DOI: 10.1007/978-3-642-12620-8].

[34] Y. Kubota, S. Inagaki, Y. Takechi, Catal. Today 226 (2014) 109. 


\section{Table 1}

Dealumination behaviors of various MSE-type zeolites during nitric acid treatments ${ }^{\text {a }}$

\begin{tabular}{ccc}
\hline $\begin{array}{c}\text { Concentration of aqueous } \\
\mathrm{HNO}_{3} \text { solution } / \mathrm{mol} \mathrm{L}^{-1}\end{array}$ & $\begin{array}{c}\text { MSE-type } \\
\text { zeolite }^{\mathrm{b}}\end{array}$ & $\mathrm{Si} / \mathrm{Al}{ }^{\mathrm{c}}$ \\
\hline 2.0 & MCM-68 & 92.9 \\
2.0 & YNU-3 & 37.5 \\
2.0 & MSE & 22.7 \\
\hline 6.0 & MCM-68 & 335.9 \\
6.7 & YNU-3 & 69.4 \\
6.0 & MSE & 66.9 \\
\hline
\end{tabular}

a. The procedure is described in the Experimental Section (2.5 and 2.7).

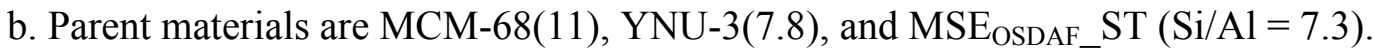

c. Si/Al ratio determined by ICP analysis after acid-treatment. 


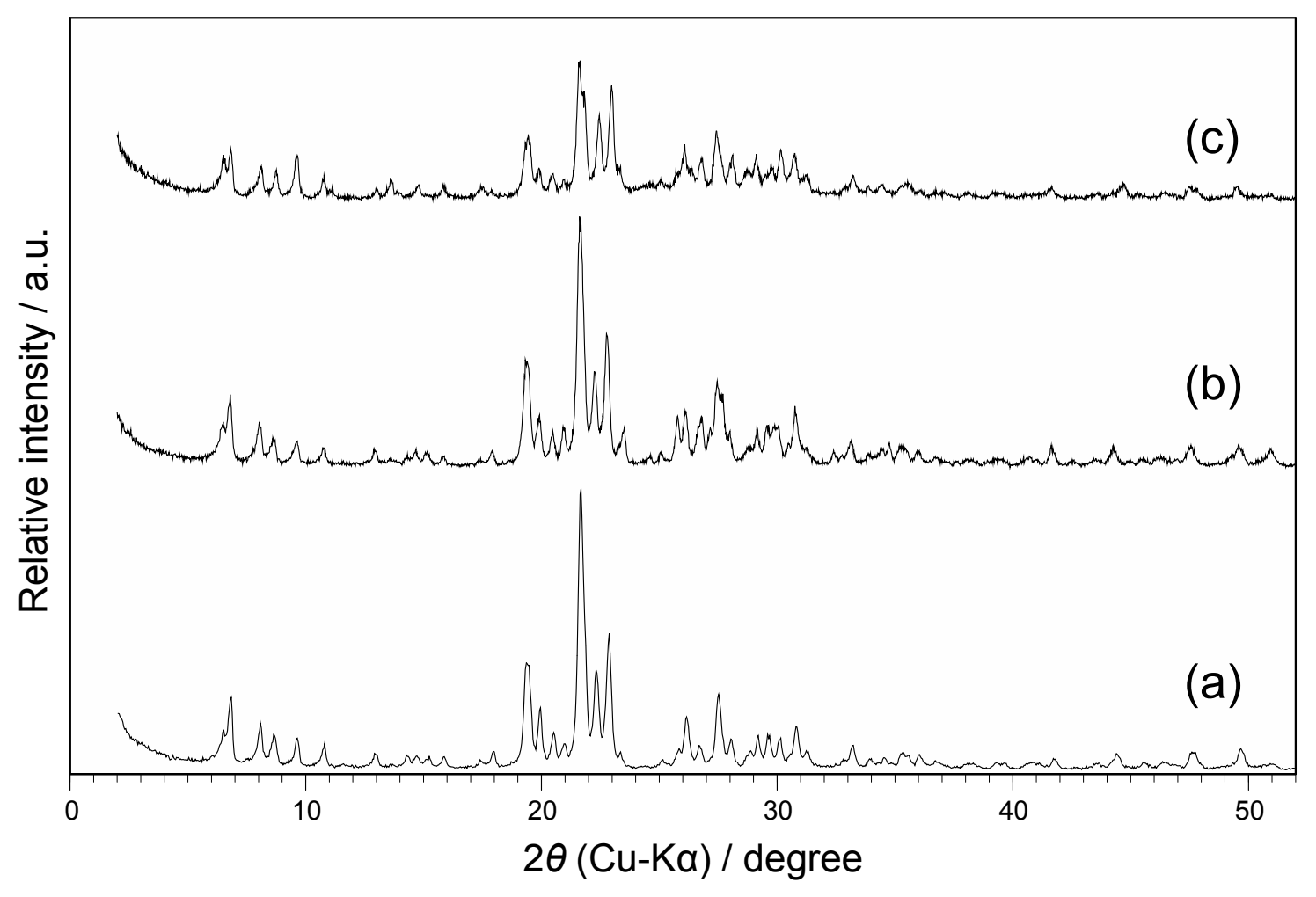

Fig. 1

XRD patterns of as-synthesized (a) MCM-68 (Si/Al = 11), (b) YNU-3 ( $\mathrm{Si} / \mathrm{Al}=7.4)$, and (c) $\operatorname{MSE}_{\mathrm{OSDAF}}(\mathrm{Si} / \mathrm{Al}=6.7)$. 


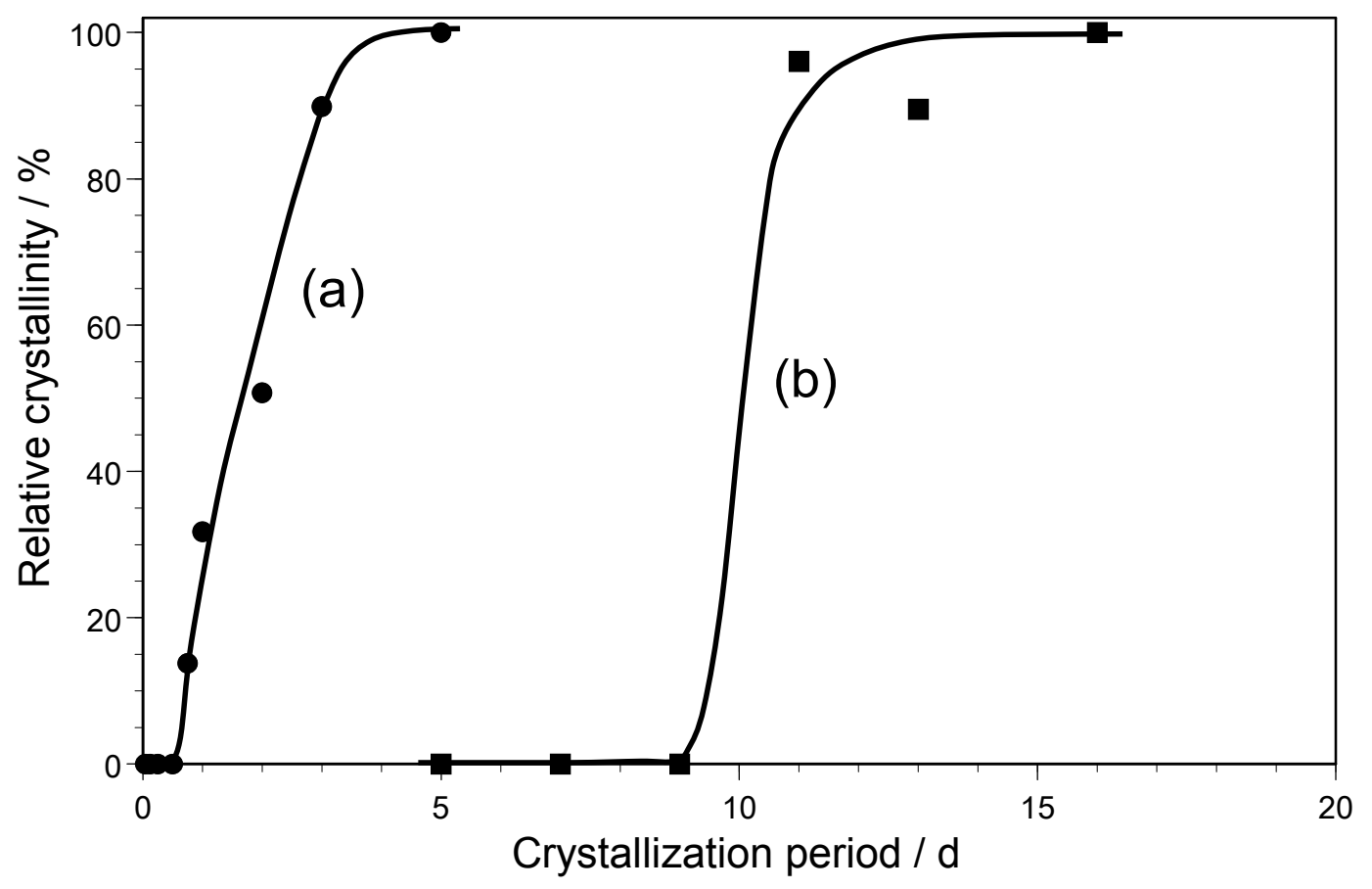

Fig. 2

Crystallization curves of (a) YNU-3 and (b) conventional MCM-68 at $160{ }^{\circ} \mathrm{C}$ under static conditions. The relative crystallinity was determined by using the intensity of the XRD peak at around 21.7 degrees in $2 \theta$ indexed to 420 in the MSE framework. 


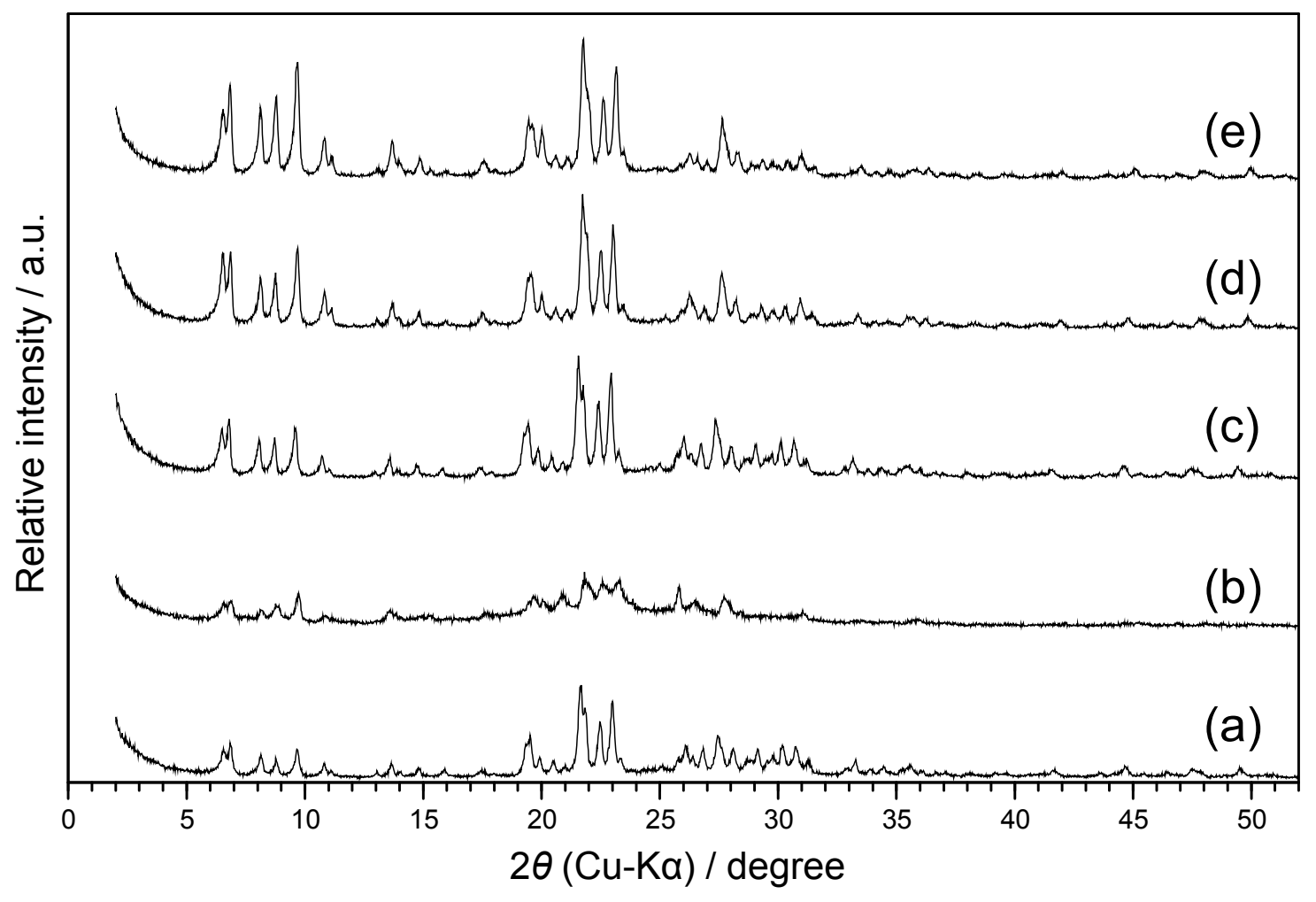

Fig. 3 Effects of post-synthesis treatments. XRD patterns and $\mathrm{Si} / \mathrm{Al}$ ratios of (a) as-synthesized MSE ${ }_{\mathrm{OSDAF}} ; \mathrm{Si} / \mathrm{Al}=6.8$, (b) sample (a) treated with $6 \mathrm{~mol} \mathrm{~L}^{-1}$ $\mathrm{HNO}_{3}$ under reflux for $2 \mathrm{~h}$, (c) MSE $\mathrm{OSDAF}_{-} \mathrm{IE} ; \mathrm{Si} / \mathrm{Al}=6.5$,

(d) MSE OSDAF_IE_ST; $_{\text {Si }} / \mathrm{Al}=6.8$ and (e) MSE $\mathrm{OSDAF}_{-} I E_{-} \mathrm{ST} \_\mathrm{AT} ; \mathrm{Si} / \mathrm{Al}=66.9$. Abbreviations are explained in the text. 
(a)

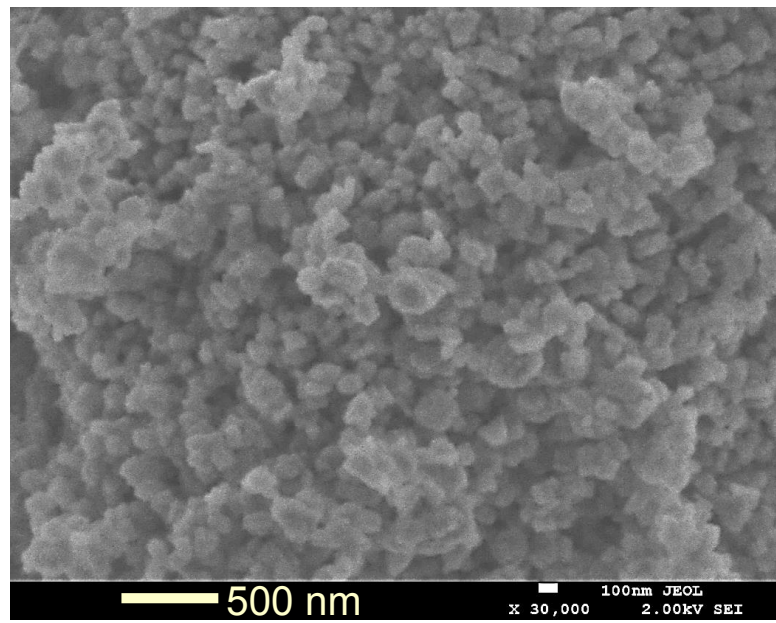

(b)

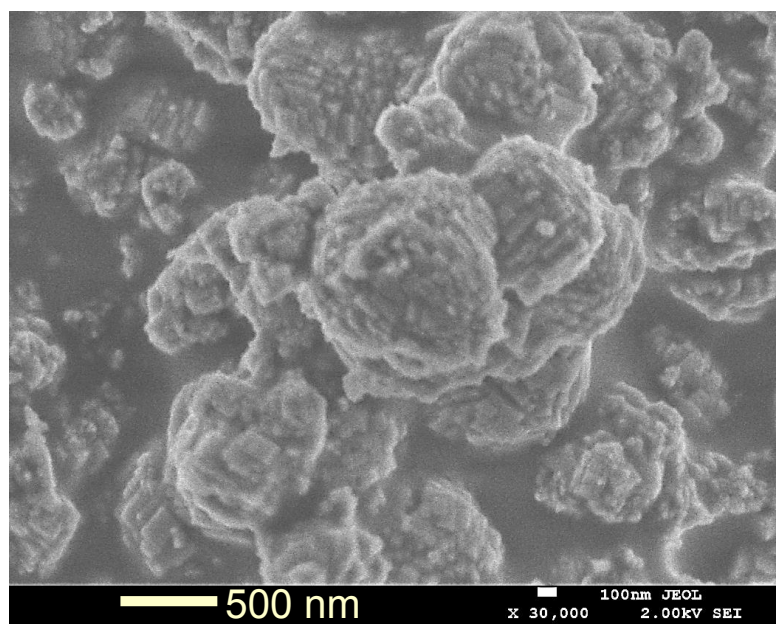

(c)

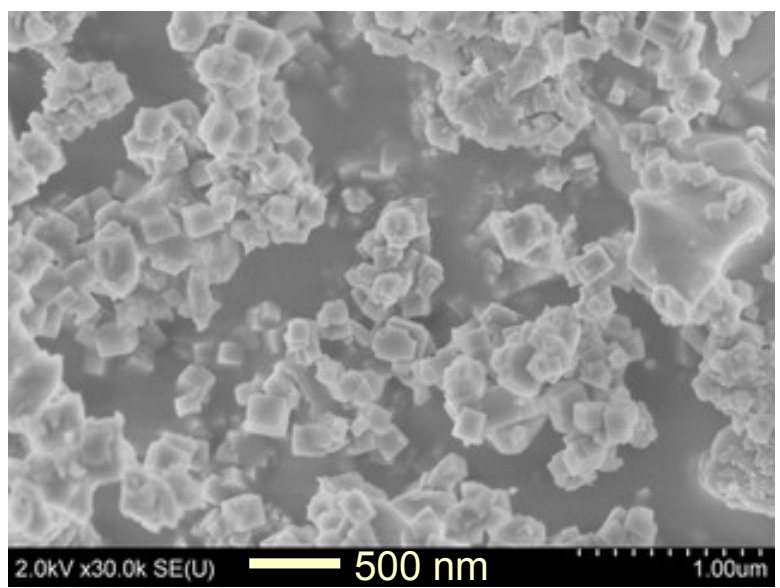

Fig. 4 Typical FE-SEM images of (a) MCM-68, (b) YNU-3, and (c) MSE OSDAF in the same magnification. Abbreviations are explained in the text. 


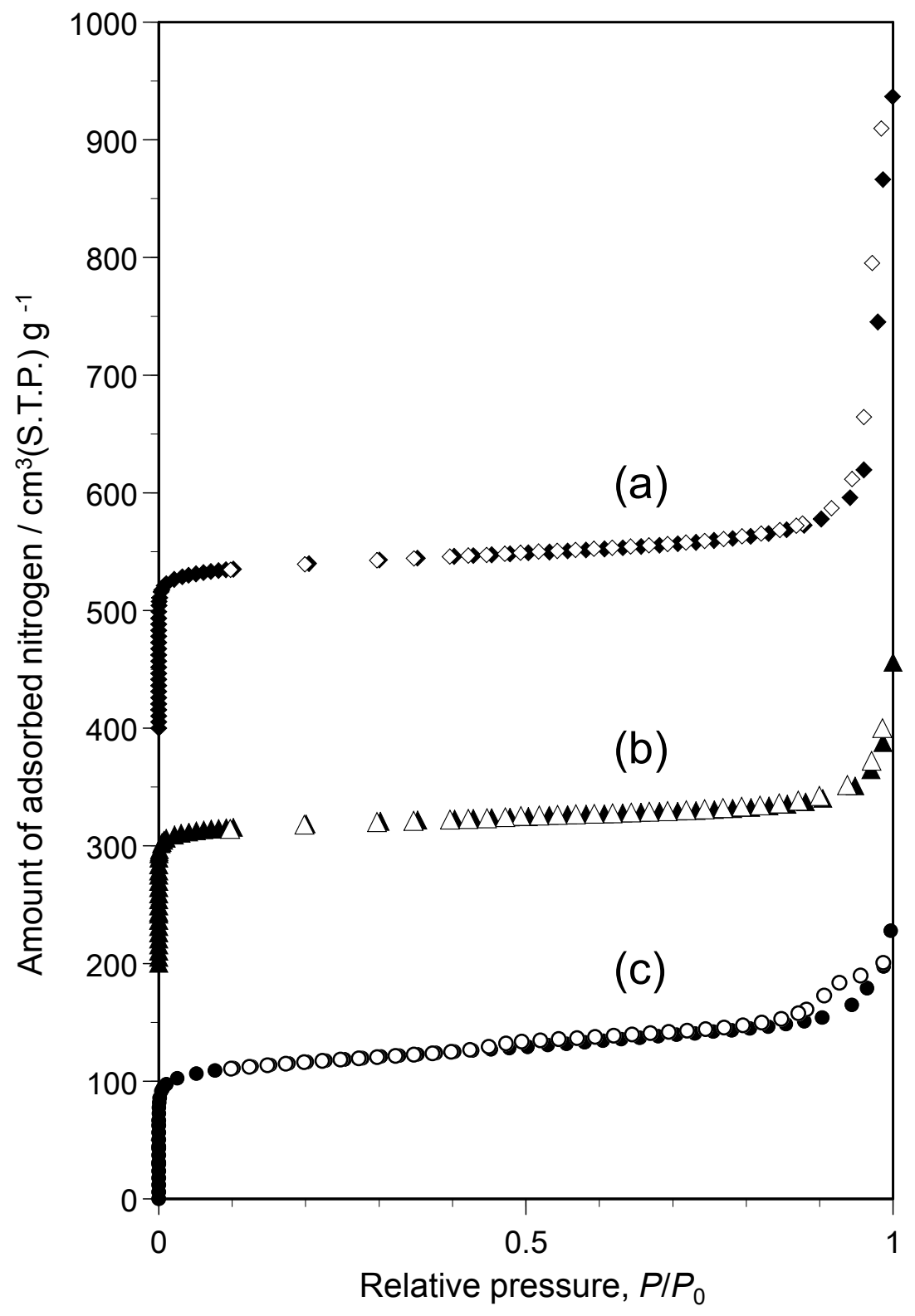

Fig. 5 Nitrogen adsorption-desorption isotherms at $-196^{\circ} \mathrm{C}$ of (a) MCM-68, (b) YNU-3, and

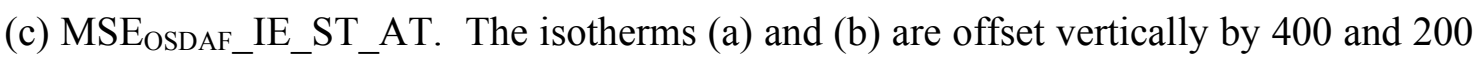
$\mathrm{cm}^{3}$ (S.T.P.) $\mathrm{g}^{-1}$, respectively. Filled and unfilled symbols indicate adsorption and desorption, respectively. The BET surface areas, corresponding micropore volumes and external surface areas estimated by the $t$-plot method were (a) $522 \mathrm{~m}^{2} \mathrm{~g}^{-1}, 0.19 \mathrm{~cm}^{3}, 59 \mathrm{~m}^{2}$ $\mathrm{g}^{-1}$, (b) $445 \mathrm{~m}^{2} \mathrm{~g}^{-1}, 0.18 \mathrm{~cm}^{3}, 30 \mathrm{~m}^{2} \mathrm{~g}^{-1}$, and (c) $430 \mathrm{~m}^{2} \mathrm{~g}^{-1}, 0.18 \mathrm{~cm}^{3}, 44 \mathrm{~m}^{2} \mathrm{~g}^{-1}$, respectively. 


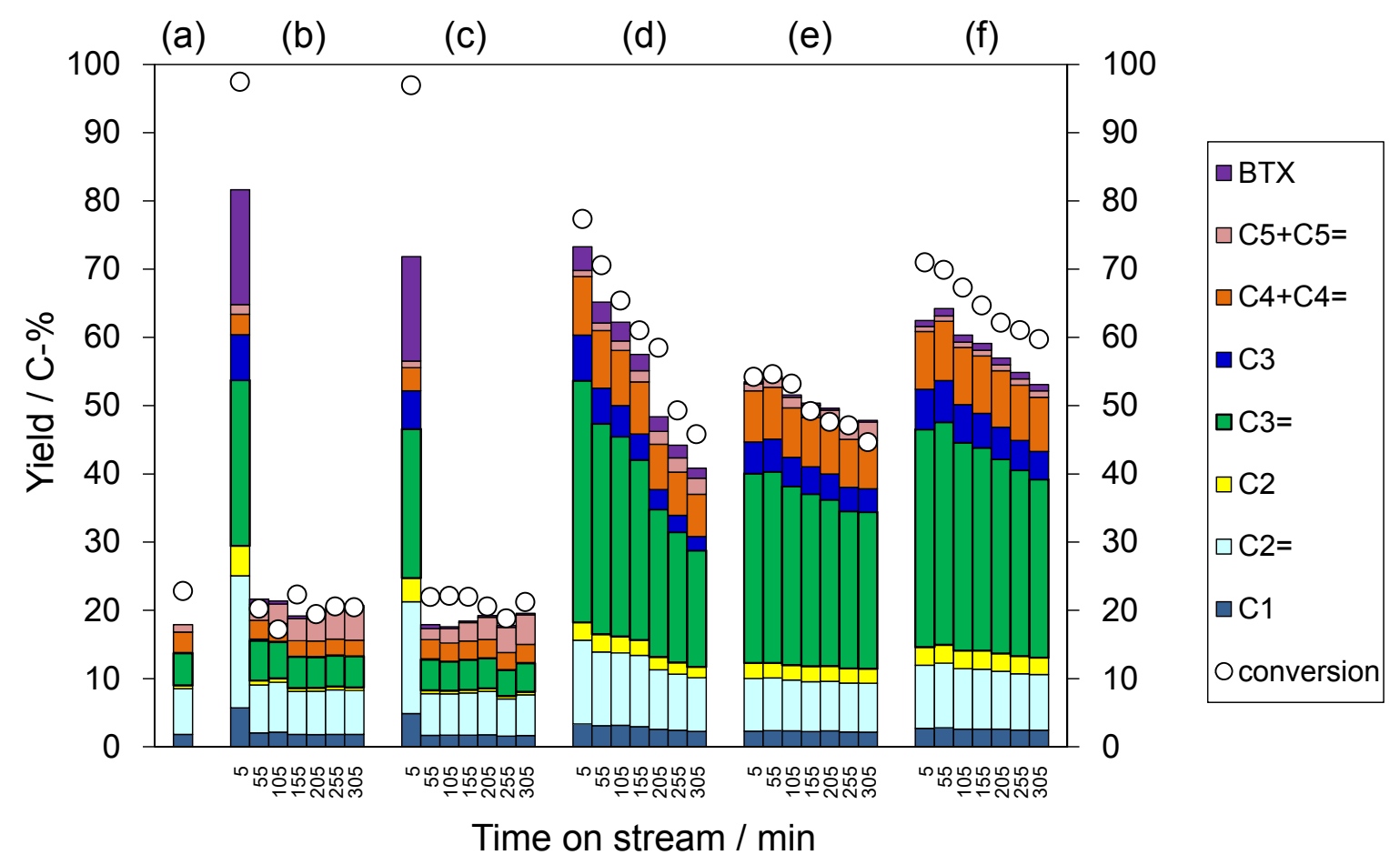

Fig. 6 Conversion and yield from the cracking of hexane (a) without catalyst and catalyzed by (b) MCM-68 (Si/Al = 11), (c) YNU-3 ( $\mathrm{Si} / \mathrm{Al}=7.4)$, (d) dealuminated MCM-68 (MCM-68_AT, Si/Al=64.5), (e) dealuminated YNU-3 (YNU-3_AT, $\mathrm{Si} / \mathrm{Al}=69.4$ ), and (f) MSE $\mathrm{OSDAF}_{-} \mathrm{IE} \_\mathrm{ST} \_\mathrm{AT}, \mathrm{Si} / \mathrm{Al}=66.9$.

Reaction conditions: catalyst, $100 \mathrm{mg}$; temperature, $650^{\circ} \mathrm{C}$; $W / F, 19.6$ g-cat h (mol-hexane) ${ }^{-1} ; p$ (hexane), $5.0 \mathrm{kPa}$; He gas flow rate, $40 \mathrm{~cm}^{3}$ (N.T.P.) $\mathrm{min}^{-1}$. 


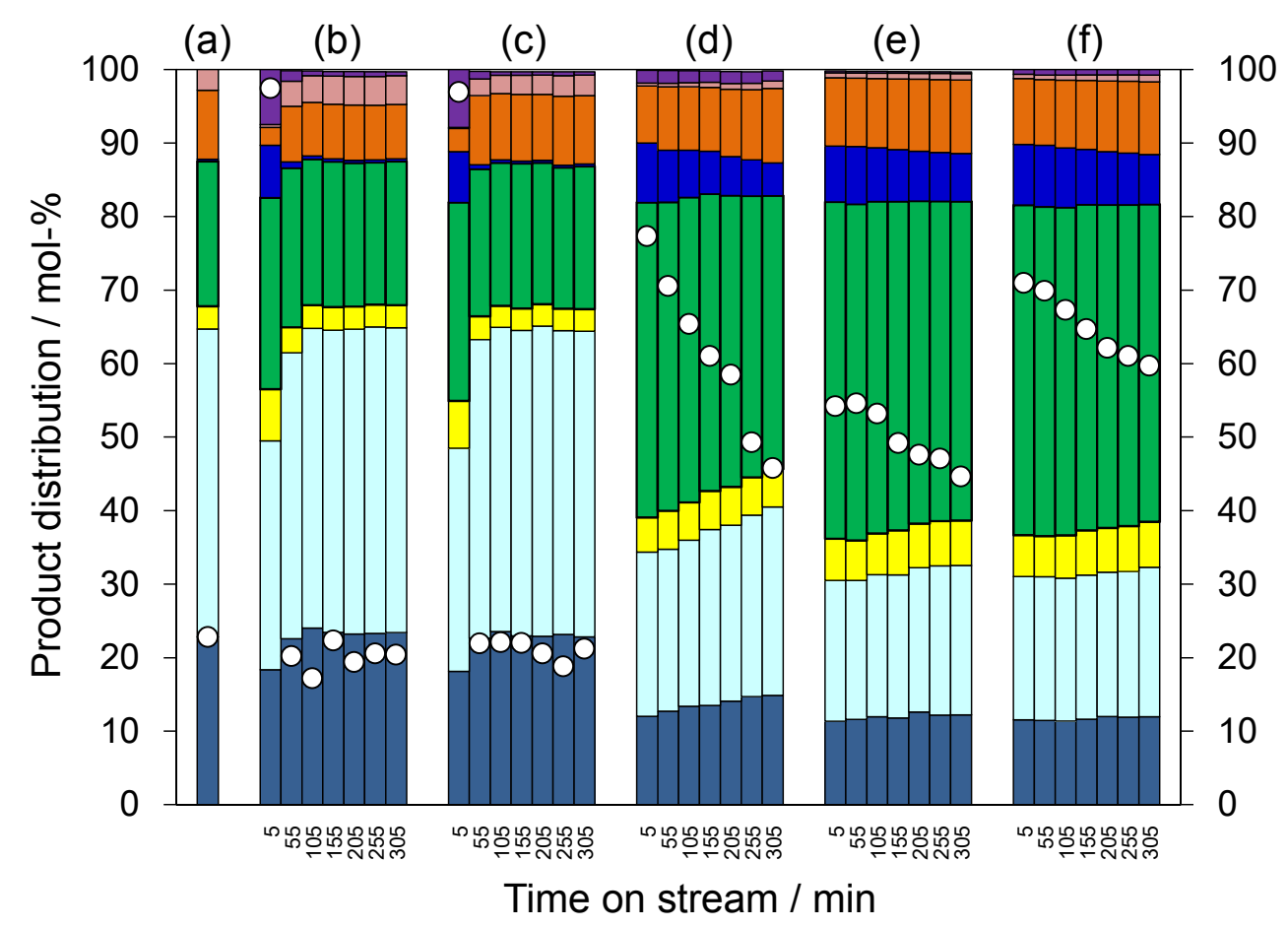

\begin{tabular}{|l|}
$\square \mathrm{BTX}$ \\
$\square \mathrm{C} 5+\mathrm{C} 5=$ \\
$\square \mathrm{C} 4+\mathrm{C} 4=$ \\
$\square \mathrm{C} 3$ \\
$\square \mathrm{C} 3=$ \\
$\square \mathrm{C} 2$ \\
$\square \mathrm{C} 2=$ \\
$\square \mathrm{C} 1$ \\
o conversion
\end{tabular}

Fig. 7 Conversion and product distribution from the cracking of hexane

(a) without catalyst and catalyzed by (b) MCM-68 ( $\mathrm{Si} / \mathrm{Al}=11)$,

(c) YNU-3 ( $\mathrm{Si} / \mathrm{Al}=7.4)$, (d) dealuminated MCM-68 (MCM-68_AT, $\mathrm{Si} / \mathrm{Al}=64.5$ ), (e) dealuminated $\mathrm{YNU}-3$ (YNU-3_AT, $\mathrm{Si} / \mathrm{Al}=69.4)$, and

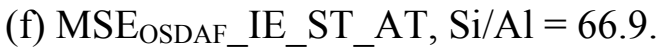

Reaction conditions: catalyst, $100 \mathrm{mg}$; temperature, $650{ }^{\circ} \mathrm{C}$; $W / F, 19.6$ g-cat h (mol-hexane) ${ }^{-1}$; $p$ (hexane), $5.0 \mathrm{kPa}$;

He gas flow rate, $40 \mathrm{~cm}^{3}$ (N.T.P.) $\mathrm{min}^{-1}$. 


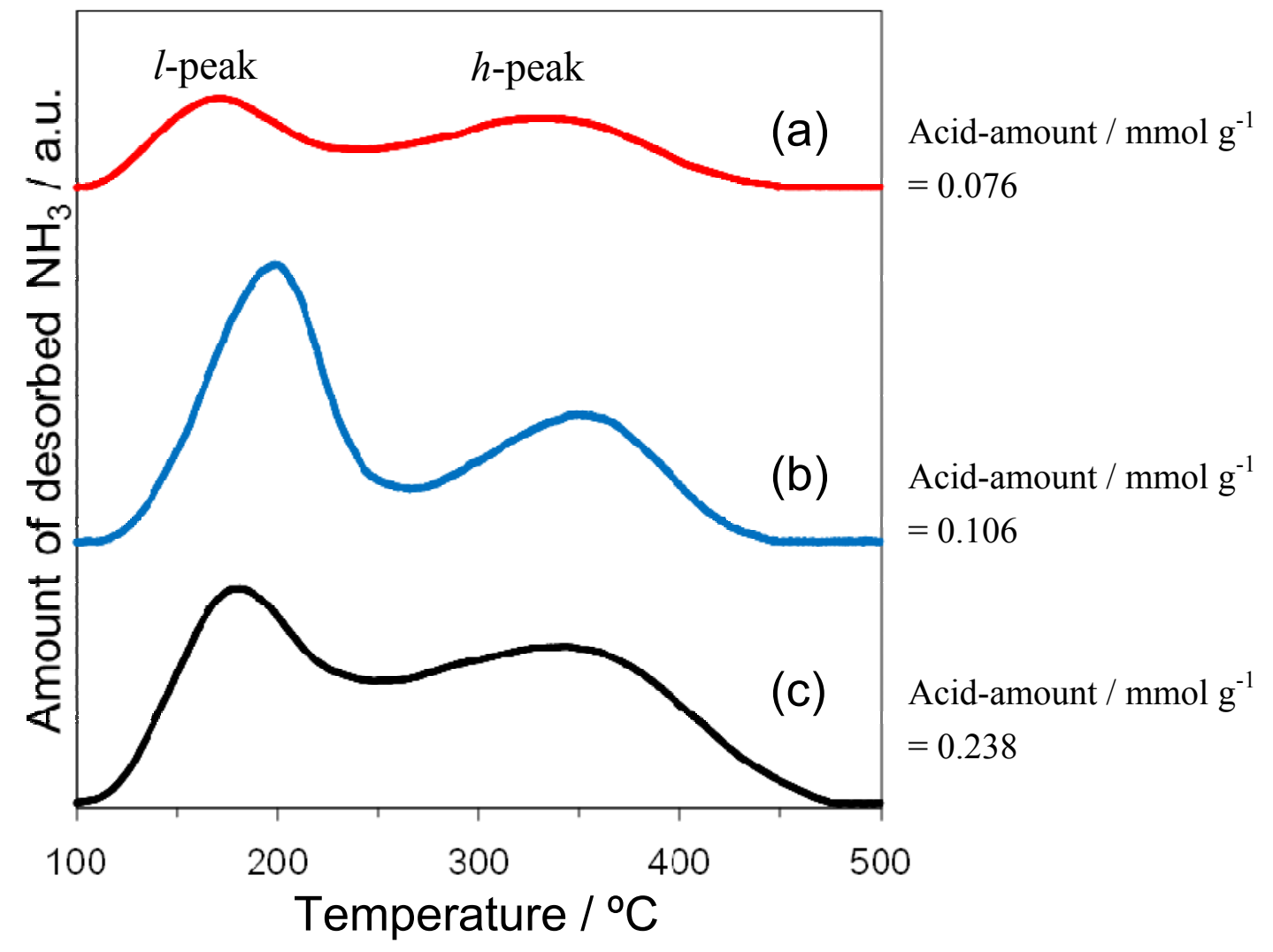

Fig. 8

$\mathrm{NH}_{3}$-TPD profiles of (a) MCM-68_AT; $\mathrm{Si} / \mathrm{Al}=64.5, \mathrm{Al}$ amount $/ \mathrm{mmol} \mathrm{g}^{-1}=0.245$ (ICP),

(b) YNU-3_AT; Si $/ \mathrm{Al}=69.4, \mathrm{Al}$ amount $/ \mathrm{mmol} \mathrm{g}^{-1}=0.237$ (ICP), and

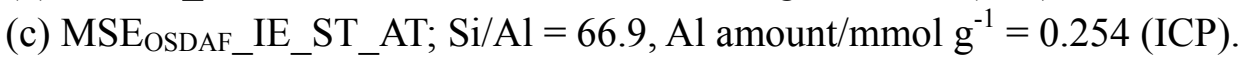

Abbreviations are explained in the text. 